\author{
W.F. Stewart · J.B. Van Rooyen - G.W. Cundiff \\ P. Abrams · A.R. Herzog · R. Corey \\ T.L. Hunt $\cdot$ A.J. Wein
}

\title{
Prevalence and burden of overactive bladder in the United States
}

Received: 5 May 2002 / Accepted: 23 August 2002 / Published online: 15 November 2002

(C) Springer-Verlag 2002

\begin{abstract}
Context: The National Overactive BLadder Evaluation (NOBLE) Program was initiated to better understand the prevalence and burden of overactive bladder in a broad spectrum of the United States population. Objective: To estimate the prevalence of overactive bladder with and without urge incontinence in the US, assess variation in prevalence by sex and other factors, and measure individual burden. Design: US national telephone survey using a clinically validated interview and a follow-up nested study comparing overactive bladder cases to sex- and age-matched controls. Setting: Noninstitutionalized US adult population. Participants: A sample of 5,204 adults $\geq 18$ years of age and representative of the US population by sex, age, and geographical region. Main outcome measures: Prevalence of overactive bladder with and without urge incontinence and risk factors for overactive bladder in the US. In the nested case-control study, SF-36, CES-D, and MOS sleep scores were used to assess impact. Results: The overall prevalence of overactive bladder
\end{abstract}

\footnotetext{
W.F. Stewart $(\bowtie) \cdot J . B$. Van Rooyen · G.W. Cundiff Department of Epidemiology,

Johns Hopkins University, 615 North Wolfe Street, Room 6039E, Baltimore, MD 21205, USA

E-mail: wstewart@jhsph.edu

Tel.: + 1-410-9553906

Fax: $+410-9550863$

W.F. Stewart

Innovative Medical Research, Towson, MD, USA

P. Abrams

Bristol Urological Institute, Bristol, UK

A.R. Herzog

University of Michigan, Ann Arbor, MI, USA

R. Corey $\cdot$ T.L. Hunt

Pharmacia Corporation, Peapack, NJ, USA

R. Corey

University of the Sciences in Philadelphia,

Philadelphia, PA, USA

A.J. Wein

University of Pennsylvania, Philadelphia, PA, USA
}

was similar between men (16.0\%) and women (16.9\%), but sex-specific prevalence differed substantially by severity of symptoms. In women, prevalence of urge incontinence increased with age from $2.0 \%$ to $19 \%$ with a marked increase after 44 years of age, and in men, increased with age from $0.3 \%$ to $8.9 \%$ with a marked increase after 64 years of age. Across all age groups, overactive bladder without urge incontinence was more common in men than in women. Overactive bladder with and without urge incontinence was associated with clinically and significantly lower SF-36 quality-of-life scores, higher CES-D depression scores, and poorer quality of sleep than matched controls. Conclusions: the NOBLE studies do not support the commonly held notion that women are considerably more likely than men to have urgency-related bladder control problems. The overall prevalence of overactive bladder does not differ by sex; however, the severity and nature of symptom expression does differ. Sex-specific anatomic differences may increase the probability that overactive bladder is expressed as urge incontinence among women compared with men. Nonetheless, overactive bladder, with and without incontinence, has a clinically significant impact on quality-of-life, quality-of-sleep, and mental health, in both men and women.

Overactive bladder $(\mathrm{OAB})$ is a common disabling condition that affects health-related quality of life (HRQL) [1]. Estimates of the prevalence and related social burden of $\mathrm{OAB}$ vary widely, in part due to variation in the assessment of symptoms, the populations surveyed, the methods used to collect data, and the criteria used to define $\mathrm{OAB}$.

Recently, the International Continence Society (ICS) derived a consensus symptomatic definition of $\mathrm{OAB}$ as urinary urgency, with or without urge incontinence, usually with urinary frequency and nocturia, in the absence of pathologic or metabolic factors that would 
explain these symptoms [2]. Urodynamically, OAB is characterized by the presence of involuntary bladder contractions that occur during bladder filling despite the patient's attempt to suppress them.

Most studies of the individual impact of OAB have been limited to patients in specialty clinics or the elderly [5] and have specifically focused on OAB with urge incontinence. The focus on urge incontinence in those who seek care raises concerns that estimates of the impact of $\mathrm{OAB}$ in the US population may be overstated. Moreover, little is known about the individual impact of OAB without urge incontinence, even though persistent episodic occurrence of urgency with either frequency or coping behaviors (e.g., frequent urination) in the absence of urinary leakage is common[1,7]. Moreover, no large-scale population-based surveys in the US have used clinically validated criteria to describe prevalence and impact of OAB.

To better understand the prevalence and impact of $\mathrm{OAB}$ in the US, we initiated the National Overactive BLadder Evaluation (NOBLE) Program. As part of this program, we developed and validated symptom-based criteria to identify individuals with OAB symptoms, and used standardized instruments to assess the impact of OAB on HRQL, quality of sleep, and depression status.

\section{Materials and methods}

Using a clinically validated computer-assisted telephone interview (CATI) questionnaire (see Appendix), we completed a US national telephone survey to estimate the prevalence of $\mathrm{OAB}$ and variation in prevalence by sex, age, and other demographic factors. In a followup to the national survey, all OAB cases and matched controls were invited to complete self-administered questionnaires to assess HRQL, quality of sleep, and depression status. The study protocol and the informed consent statement for each study were approved by the Johns Hopkins University School of Medicine and Essex Institutional Review Boards. In all studies, subjects gave informed verbal and/or written consent before data collection was initiated.

\section{The CATI questionnaire}

The CATI questionnaire was developed and evaluated for reliability and clinical validity in advance of the national survey. Clinical and epidemiologic experts reviewed and revised a preliminary draft of the CATI questionnaire, based, in part, on results from a series of focus groups that included individuals with and without OAB. The CATI instrument included questions about demographics, work status, childbearing history, exercise, social activities, sleep habits, and fluid intake. Questions are available upon request. The CATI included questions about the following potential OAB symptoms: frequency (6 questions), nocturia (7 questions), urgency (12 questions), $\mathrm{OAB}$ with urge incontinence (8 questions), stress incontinence (3 questions), and coping behaviors (6 questions). The interview also included questions about urinary symptoms that may be associated with potential prostate problems (men only), a "burning" feeling or pain when urinating, and a doctor-diagnosed urinary tract infection in the previous 4 weeks. In addition, the interview included questions about physician-diagnosed medical conditions (i.e., diabetes, congestive heart failure, multiple sclerosis, Parkinson's disease, spinal cord injury, cancer, and interstitial cystitis). All questions, except those concerning physician-diagnosed medical conditions, referred to the 4-week period preceding the telephone interview.
CATI criteria for OAB were based on a prior clinical validation study (see Appendix). In the population-based validation study, $\mathrm{OAB}$ without urge incontinence was defined by a feeling of urgency four or more times in the past 4 weeks and either more than eight micturitions per day or the use of at least one of the following coping strategies: restricting fluid intake, locating bathrooms in a new place, limiting travel, or defensive voiding. OAB with urge incontinence included the criteria for $\mathrm{OAB}$ without urge incontinence plus three or more episodes of urinary leakage in the past 4 weeks that was typical (i.e., frequency of episodes) and was not exclusively due to stress incontinence. A final diagnosis of OAB was made after excluding secondary causes of symptoms, including the following: diabetes, congestive heart failure, cancer, bladder surgery, previously diagnosed enlarged prostate, urinary tract infection (i.e., urine test and questions about burning pain on urination), interstitial cystitis, pregnancy or recent birth, medications, and excessive fluid intake. The CATI criteria used in the national survey were designed to optimize sensitivity and specificity of the clinician's diagnosis in the clinical validation study.

\section{US national telephone survey and nested case-control study}

A US nationwide random sample of telephone numbers was obtained using the Gensys sampling method to conduct a survey of English-speaking adults 18 years of age or older. A quota method $[9,15]$ was used to capture a sample representative of the US population with regard to sex, age (18-24, 25-44, 45-64, 65-74, $75+$ years), and geographic region (northeast, midwest, south, and west). Up to ten attempts were made to contact each household, and one adult was interviewed per household. If more than one eligible adult household member was available, we selected the one whose date of birth was closest to the date of the interview to maintain a random selection of a household member. Using a predetermined algorithm, trained interviewers conducted a $10-$ to 20-min interview of participants.

From the national survey, all individuals with $\mathrm{OAB}$ and a sexand age-matched sample of OAB-negative individuals were invited to participate in a nested case-control follow-up study to assess the impact of OAB on HRQL. Participants completed self-administered questionnaires to assess quality-of-life (SF-36) [17], depression status [Center for Epidemiologic Studies Depression Scale (CES-D)] [10], and sleep quality [Medical Outcomes Sleep Scale (MOS-Sleep)] [6].

\section{Data analysis}

Unadjusted sex-specific prevalence estimates of $\mathrm{OAB}$ with and without urge incontinence were derived by age, education, income, race, body-mass index, prostate problems, and lower urinary tract infections. Women who were pregnant or who recently gave birth (i.e., within 6 months preceding the interview) were excluded when estimating prevalence of OAB. To determine if $\mathrm{OAB}$ varied by demographic and other features, we analyzed data using a generalized linear model framework (SAS Proc GENMOD, version 8). The $\log$ of the expectation of each binary response variable (i.e., $\mathrm{OAB}$ with urge incontinence and $\mathrm{OAB}$ without urge incontinence) was modeled as linear functions of the explanatory variable. Loglink was used so that parameters could be interpreted as prevalence ratios (i.e., OAB prevalence in one group divided by OAB prevalence in the reference group) rather than as odds ratios. For regression analysis, subjects with unknown (or refused) responses for age were assigned the median age value. Subjects with unknown values for race and other covariates were grouped with the largest subgroup within that variable.

In the analysis of the relation between $\mathrm{OAB}$ prevalence and other factors (i.e., age, education, income, race, body mass index, and lower urinary tract disease other than $\mathrm{OAB}$ ), covariates were first individually evaluated in regression models. Statistically significant or borderline significant covariates were retained in each model. Variables that improved the fit of the model to the data varied by sex and by OAB with or without urge incontinence. The 
prevalence ratios for both $\mathrm{OAB}$ with incontinence and $\mathrm{OAB}$ without incontinence were adjusted for age, education, and income. The chi-square test was used to determine whether a single variable significantly improved the fit of the log-linear model to the data.

In the nested case-control study, mean SF-36 subscores, mean CES-D scores, and the mean MOS-sleep score were compared among participants who had $\mathrm{OAB}$ with urge incontinence, those with $\mathrm{OAB}$ without urge incontinence, and $\mathrm{OAB}$-negative controls. Differences between $\mathrm{OAB}$ cases and controls and between $\mathrm{OAB}$ cases with or without urge incontinence were adjusted for the above noted covariates, including comorbidities. Results were compared using the chi-square test.

\section{Results}

\section{Participants}

A total of 17,231 households were contacted (includes 2,427 households where eligible members met criteria for region-sex-age-specific strata in which the sampling quota was filled) between November 2000 and January 2001 . The process for selecting participants is shown in Fig. 1. The sex and age (Table 1), and regional distribution (data available upon request) of the study participants were representative of the noninstitutionalized US population.

Prevalence and adjusted prevalence ratios by sex

A total of $857(16.5 \%)$ individuals met the criteria for $\mathrm{OAB} ; 319(6.1 \%)$ met the criteria for $\mathrm{OAB}$ with urge incontinence, and $538(10.4 \%)$ met criteria for OAB without urge incontinence (Table 1). Of the participants who had OAB with urge incontinence, $45 \%$ had mixed incontinence symptoms - urine leakage occurring not only with urge, but also with stress incontinence (symptoms of incontinence due to increased abdominal pressure frequently associated with coughing, sneezing, exercising, or lifting).

The prevalence of $\mathrm{OAB}$ was $16.9 \%$ in women and $16.0 \%$ in men. However, the prevalence of OAB with and without urge incontinence differed substantially in men and women. In women, OAB prevalence with and without urge incontinence was similar $(9.3 \%$ and $7.6 \%$, respectively). In men, prevalence of $\mathrm{OAB}$ without urge incontinence was higher than that of $\mathrm{OAB}$ with urge incontinence (13.4\% and $2.6 \%$, respectively). Sex-specific prevalence estimates and adjusted prevalence ratios did not vary by race, but did vary considerably by other factors (Table 2). Prevalence and prevalence ratios were inversely related to increasing education, a pattern that was more apparent among women who had OAB with urge incontinence. In women, but not men, the prevalence of $\mathrm{OAB}$ with urge incontinence increased in relation to increasing body mass index. The prevalence of $\mathrm{OAB}$ with urge incontinence in participants with BMIs $\geq 30$ was 2.2-times higher than the prevalence among those with BMIs $<24$.

The age-specific prevalence of OAB was similar for men and women (Fig. 2a). However, age patterns differed by sex and by type of OAB. The prevalence of $\mathrm{OAB}$ with urge incontinence displays a steeper age-related increase among women than among men (Fig. 2b) and the sex difference is statistically significant $(P<0.0001)$. In women, OAB with urge incontinence increased more than nine-fold, from $2.0 \%$ in those 18 24 years of age to $19.1 \%$ among those $65-74$ years of age. In contrast, a substantial increase in prevalence of $\mathrm{OAB}$ with urge incontinence among men did not occur until 65 years of age, reaching $8.2 \%$ for ages 65 74 years, and $10.2 \%$ for those 75 years and older.
Fig. 1 Participant sample selection

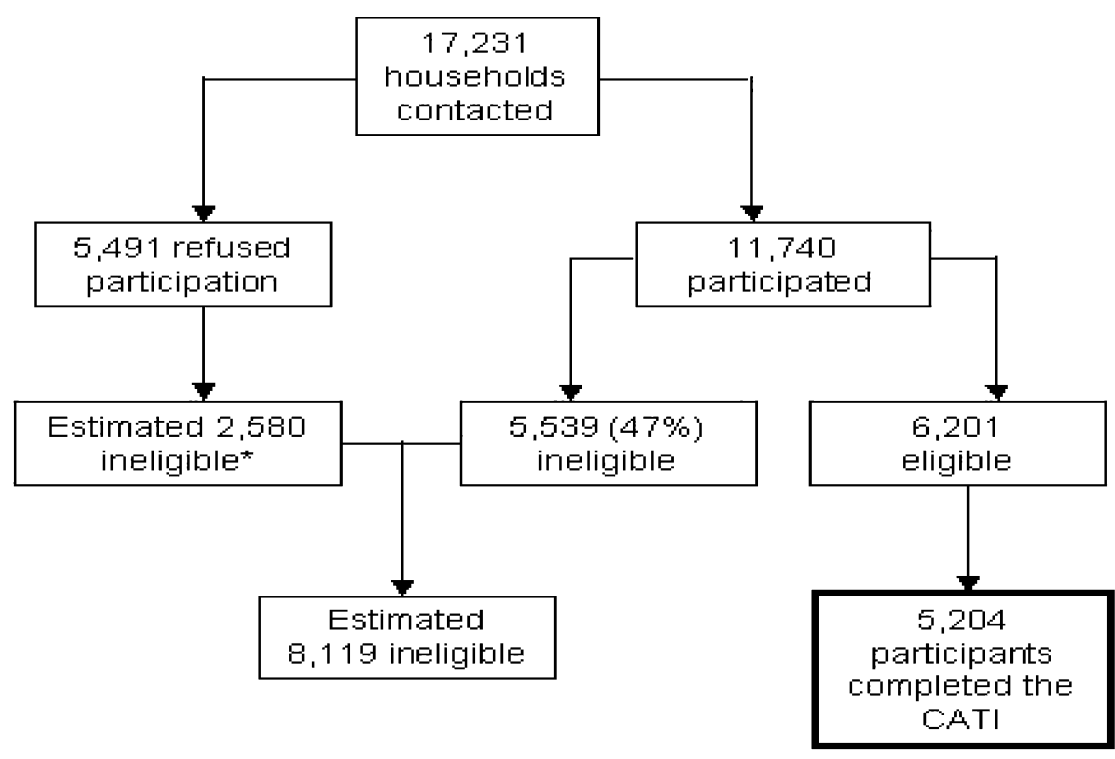


Table 1 Sex-specific distribution of participants in the US National Survey of OAB by demographic and other factors

\begin{tabular}{|c|c|c|c|}
\hline Characteristic, $n(\%)$ & $\operatorname{Men}(n=2469)$ & Women $(n=2735)$ & Total $(N=5204)$ \\
\hline $\begin{array}{l}\text { Age, years } \\
<25 \\
25-34 \\
35-44 \\
45-54 \\
55-64 \\
65-75 \\
75+ \\
\text { Unknown }\end{array}$ & $\begin{array}{l}320(13.0) \\
46018.6) \\
578(23.4) \\
443(17.9) \\
292(11.8) \\
232(9.4) \\
128(5.2) \\
16(0.6)\end{array}$ & $\begin{array}{l}307(11.2) \\
419(15.3) \\
606(22.2) \\
451(16.5) \\
385(14.1) \\
304(11.1) \\
234(8.6) \\
29(1.1)\end{array}$ & $\begin{array}{r}627(12.0) \\
879(16.9) \\
1184(22.8) \\
894(17.2) \\
677(13.0) \\
536(10.3) \\
362(7.0) \\
45(0.9)\end{array}$ \\
\hline $\begin{array}{l}\text { Education } \\
<\text { High school } \\
\text { High school graduate } \\
\text { Technical/some college } \\
\text { College graduate } \\
\text { Unknown }\end{array}$ & $\begin{array}{l}201(8.1) \\
782(31.7) \\
607(24.6) \\
869(35.2) \\
10(0.4)\end{array}$ & $\begin{array}{c}278(10.2) \\
916(33.5) \\
733(26.8) \\
796(29.1) \\
12(0.4)\end{array}$ & $\begin{aligned} 479 & (9.2) \\
1698 & (32.6) \\
1340 & (25.7) \\
1665 & (32.0) \\
22 & (0.4)\end{aligned}$ \\
\hline $\begin{array}{l}\begin{array}{l}\text { Household income } \\
\quad<\$ 20,000\end{array} \\
\$ 20,000-\$ 29,999 \\
\$ 30,000-\$ 49,999 \\
\$ 50,000+ \\
\text { Refused } \\
\text { Unknown }\end{array}$ & $\begin{array}{l}320(13.0) \\
253(10.2) \\
544(22.0) \\
919(37.2) \\
327(13.2) \\
106(4.3)\end{array}$ & $\begin{array}{l}523(19.1) \\
333(12.2) \\
525(19.2) \\
681(24.9) \\
524(19.2) \\
149(5.4)\end{array}$ & $\begin{array}{r}843(16.2) \\
586(11.3) \\
1069(20.5) \\
1600(30.7) \\
851(16.4) \\
255(4.9)\end{array}$ \\
\hline $\begin{array}{l}\text { Race } \\
\text { White } \\
\text { Black } \\
\text { Hispanic } \\
\text { Other } \\
\text { Unknown } \\
\text { Body mass index } \\
<22.0 \\
22.0-23.9 \\
24.0-25.9 \\
26.0-29.9 \\
30+ \\
\text { Refused }\end{array}$ & $\begin{array}{r}1942(78.7) \\
221(9.0) \\
132(5.3) \\
147(5.9) \\
27(1.1) \\
\\
262(10.6) \\
390(15.8) \\
545(22.1) \\
769(31.1) \\
503(20.4) \\
-\end{array}$ & $\begin{array}{r}2235(81.7) \\
249(9.1) \\
116(4.2) \\
103(3.8) \\
32(1.2) \\
\\
691(25.3) \\
429(15.7) \\
435(15.9) \\
527(19.3) \\
651(23.8) \\
2(0.1)\end{array}$ & $\begin{array}{r}4177(80.3) \\
470(9.0) \\
248(4.8) \\
250(4.8) \\
59(1.1) \\
\\
953(18.3) \\
819(15.7) \\
980(18.8) \\
1296(24.9) \\
1154(22.2) \\
2(0.05)\end{array}$ \\
\hline $\begin{array}{l}\text { Prostate problems } \\
\text { No } \\
\text { Yes } \\
\text { Refused } \\
\text { Unknown } \\
\text { Not applicable }\end{array}$ & $\begin{aligned} 2228 & (90.2) \\
228 & (9.2) \\
5 & (0.2) \\
8 & (0.3) \\
- & \end{aligned}$ & $\begin{array}{l}- \\
- \\
- \\
- \\
2735(100.0)\end{array}$ & $\begin{array}{c}2228(42.8) \\
228(4.4) \\
5(0.1) \\
8(0.2) \\
2735(52.5)\end{array}$ \\
\hline $\begin{array}{l}\text { Urinary tract infection } \\
\text { No } \\
\text { Yes } \\
\text { Refused } \\
\text { Unknown }\end{array}$ & $\begin{array}{l}\text { weeks) } \\
2433(98.5) \\
18(0.7) \\
11(0.4) \\
7(0.3)\end{array}$ & $\begin{aligned} 2623 & (95.9) \\
91 & (3.3) \\
18 & (0.7) \\
3 & (0.1)\end{aligned}$ & $\begin{array}{r}5056(97.2) \\
109(2.1) \\
29(0.6) \\
10(0.2)\end{array}$ \\
\hline $\begin{array}{l}\text { OAB Status, } n(\%) \\
\text { Normal } \\
\text { OAB with urge UI } \\
\text { OAB without urge UI }\end{array}$ & $\begin{array}{c}2075(84.0) \\
65(2.6) \\
329(13.4)\end{array}$ & $\begin{array}{c}2272(83.1) \\
254(9.3) \\
209(7.6)\end{array}$ & $\begin{array}{c}4347(83.5) \\
319(6.1) \\
538(10.3)\end{array}$ \\
\hline
\end{tabular}

A different sex-specific age pattern emerged for $\mathrm{OAB}$ without urge incontinence (Fig. 2c). The prevalence of OAB without urge incontinence showed a steeper increase by age in men than in women and was significantly different by sex $(P<0.0001)$. In men, OAB without urge incontinence increased approximately three-fold from $8.5 \%$ below 45 years of age to $21.8 \%$ after 55 years of age, whereas OAB without urge incontinence gradually increased in women less than 44 years of age and reached a plateau in women over the age of 44 years.
Relation of OAB with lower urinary tract infections and prostate problems

$\mathrm{OAB}$ with incontinence was more common among women with a history of urinary tract infections in the previous 4 weeks (prevalence ratio $=2.7 ; 95 \% \mathrm{CI}$ : 1.9 3.7), but was not associated with an increased prevalence of OAB without urge incontinence. In men, recent urinary tract infections were associated with $\mathrm{OAB}$ without urge incontinence (prevalence ratio $=2.9$; 95\% CI: $1.6-$ 5.0). Prevalence ratios for $\mathrm{OAB}$ with urge incontinence 
Table 2 OAB prevalence and adjusted prevalence ratios for women and men for demographic factors

\begin{tabular}{|c|c|c|c|c|c|c|c|c|}
\hline & \multicolumn{4}{|c|}{ OAB with urge incontinence $(n=319)$} & \multicolumn{4}{|c|}{ OAB without urge incontinence $(n=545)$} \\
\hline & \multicolumn{2}{|c|}{ Women $(n=254)$} & \multicolumn{2}{|c|}{ Men $(n=65)$} & \multicolumn{2}{|c|}{ Women $(n=209)$} & \multicolumn{2}{|c|}{ Men $(n=336)$} \\
\hline & $\mathrm{P}$ & PR $(95 \% \mathrm{CI})$ & $\mathrm{P}$ & PR $(95 \%$ CI) & $\mathrm{P}$ & PR $(95 \% \mathrm{CI})$ & $\mathrm{P}$ & PR $(95 \% \mathrm{CI})$ \\
\hline \multicolumn{9}{|l|}{ Education } \\
\hline$<$ High school & 16.2 & $1.6(1.1-2.4)$ & 4.0 & $0.8(0.3-1.8)$ & 9.7 & $1.8(1.1-2.8)$ & 14.4 & $1.0(0.7-1.5)$ \\
\hline High school graduation & 10.0 & $1.2(0.8-1.7)$ & 2.8 & $0.9(0.5-1.7)$ & 8.2 & $1.6(1.1-2.3)$ & 12.9 & $1.1(0.9-1.5)$ \\
\hline Tech/college & 9.1 & $1.3(0.9-1.8)$ & 2.1 & $0.7(0.3-1.3)$ & 8.2 & $1.6(1.0-2.4)$ & 16.1 & $1.4(1.0-1.8)$ \\
\hline College graduation & 6.3 & $*$ & 2.5 & $*$ & 5.5 & $*$ & 11.6 & * \\
\hline \multicolumn{9}{|l|}{ Income } \\
\hline$<\$ 20,000$ & 14.1 & $1.2(0.8-1.8)$ & 5.3 & $2.6(1.2-5.6)$ & 8.2 & $0.6(0.4-1.0)$ & 17.2 & $1.3(0.9-1.8)$ \\
\hline$\$ 20,000-\$ 29,999$ & 9.0 & $1.0(0.7-1.7)$ & 4.7 & $2.8(1.3-6.2)$ & 7.5 & $0.8(0.5-1.2)$ & 16.2 & $1.3(1.0-1.9)$ \\
\hline$\$ 30,000-\$ 49,999$ & 9.3 & $1.2(0.8-1.8)$ & 2.4 & $1.5(0.7-3.2)$ & 6.9 & $0.7(0.5-1.1)$ & 11.9 & $1.0(0.7-1.3)$ \\
\hline$>\$ 50,000$ & 6.5 & $*$ & 1.6 & $*$ & 8.1 & $*$ & 12.4 & $*$ \\
\hline Refused & 8.5 & $0.8(0.6-1.2)$ & 1.8 & $0.9(0.4-2.1)$ & 7.4 & $0.7(0.4-1.0)$ & 12.5 & $0.9(0.7-1.3)$ \\
\hline \multicolumn{9}{|l|}{ Race } \\
\hline White & 9.9 & $1.3(0.9-1.8)$ & 2.7 & $0.9(0.5-1.7)$ & 7.7 & $0.8(0.6-1.1)$ & 13.8 & $1.0(0.8-1.4)$ \\
\hline Other & 6.6 & $*$ & 2.2 & $*$ & 7.9 & $*$ & 11.8 & \\
\hline \multicolumn{9}{|l|}{ BMI } \\
\hline$<24$ & 5.3 & $*$ & 2.6 & * & 7.3 & * & 12.1 & * \\
\hline $24-30$ & 10.2 & $1.5(1.1-2.0)$ & 2.2 & $0.8(0.4-1.4)$ & 6.9 & $0.8(0.6-1.2)$ & 13.3 & $1.0(0.8-1.3)$ \\
\hline$>30$ & 14.9 & $2.2(1.6-3.0)$ & 3.8 & $1.4(0.7-2.7)$ & 9.2 & $1.1(0.8-1.6)$ & 14.9 & $1.2(0.9-1.6)$ \\
\hline \multicolumn{9}{|l|}{ Prostate problems } \\
\hline No & - & - & 1.4 & $*$ & - & - & 11.9 & $*$ \\
\hline Yes & - & - & 13.6 & $4.7(2.7-8.2)$ & - & - & 26.3 & $1.5(1.2-2.0)$ \\
\hline \multicolumn{9}{|l|}{ UTI (past 4 weeks) } \\
\hline No & 8.7 & $*$ & 2.6 & $*$ & 7.7 & $*$ & 13.0 & $*$ \\
\hline Yes & 27.5 & $2.7(1.9-3.7)$ & 5.6 & $2.1(0.3-14.4)$ & 7.7 & $0.9(0.5-1.9)$ & 38.9 & $2.9(1.6-5.0)$ \\
\hline
\end{tabular}

* Reference group used for calculation of prevalence ratio; $\mathrm{P}=$ prevalence; $\mathrm{PR}=$ prevalence ratio

(4.7; 95\% CI: $2.7-8.2)$ and for OAB without incontinence $(1.5 ; 95 \% \mathrm{CI}: 1.2-2.0)$ were significantly elevated for men who self-reported with a history of prostate problems (Table 2).

\section{Individual Impact of $\mathrm{OAB}$}

Participants in the nested case-control study included 169 $(18.3 \%)$ subjects who had OAB with urge incontinence, $228(24.8 \%)$ subjects who had OAB without urge incontinence, and $522(56.8 \%)$ age- and sex-matched OAB-negative controls. Among those invited, $46 \%$ of $\mathrm{OAB}$ cases and $58 \%$ of controls participated in the nested study. Those who returned the SF-36, CES-D, and MOSsleep questionnaires were more likely to be older, women, and white. Nonetheless, demographic characteristics were similar between participating controls and $\mathrm{OAB}$ cases. Moreover, each group was representative of participants in the CATI survey for the following bladder control variables: reported micturitions per day, number of days of nocturnal urination, number of urgency episodes, number of leakage episodes, waiting time to urinate with feeling of urgency, and use of coping strategies (data are available upon request).

Women who had OAB with or without urge incontinence had significantly worse scores than OAB-negative controls on the SF-36 physical and mental scales, after adjusting for other covariates including co-morbid illnesses (Fig. 3). They also had worse CES-D and quality-of-sleep scores (Table 3). Women who had OAB with urge incontinence did not differ from women without urge incontinence except that women with urge incontinence had a significantly lower score $(P<0.03)$ on the SF-36 physical health summary score.

Men who had OAB with and without urge incontinence had significantly poorer scores on all outcome measures compared with matched OAB-negative controls. Men who had OAB with urge incontinence had significantly poorer scores on the CES-D scale $(P<0.05)$ and the MOS-sleep scale $(P<0.05)$ compared with men who had OAB without urge incontinence. A borderline significant difference was observed for the SF-36 physical health score $(P=0.07$; Table 3$)$.

SF-36 scores for all domains were lowest for those who had OAB with urge incontinence (Figure 3). Clinically significant differences (i.e., $>5$ points) in mean SF-36 scores for all domains were observed for OAB cases with urge incontinence versus $\mathrm{OAB}$-negative controls. Differences between OAB without urge incontinence and OAB-negative controls were clinically significant for all SF-36 domains except mental health (4.6-point difference). Differences greater than 10 points between $\mathrm{OAB}$ without urge incontinence and $\mathrm{OAB}$ negative controls were observed for both role function (role of physical health in ability to carry out daily 

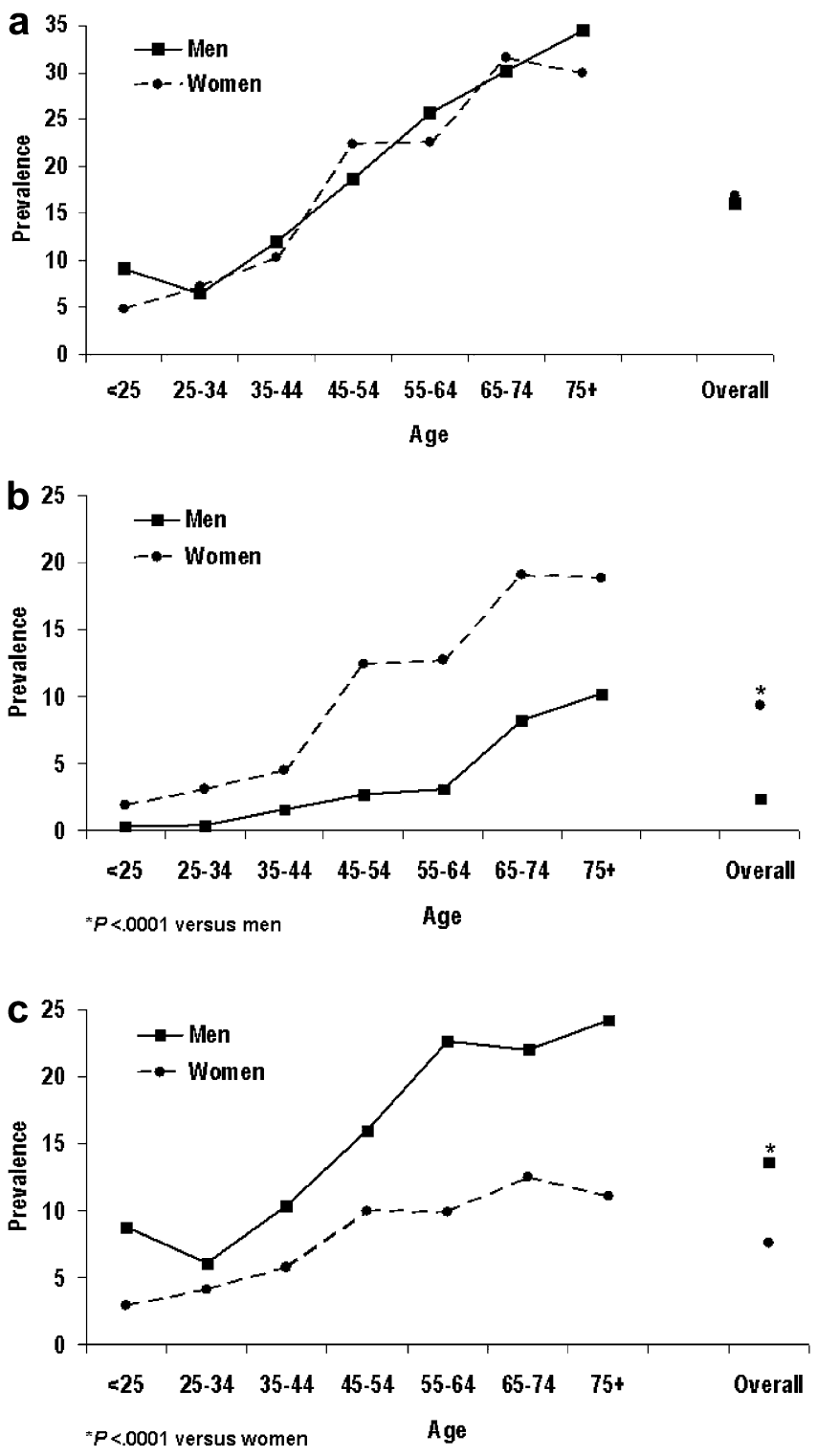

Fig. 2a-c Age- and sex-specific prevalence of OAB. a overall; b with urge incontinence; c without urge incontinence

activities; 12.2-point difference) and role emotional (role of emotional health in ability to carry out daily activities; 12.0-point difference). There were clinically significant differences in mean SF-36 scores between OAB with urge incontinence and $\mathrm{OAB}$ without urge incontinence for all SF-36 domains except mental health (3.6-point difference) (Figure 3).

\section{Discussion}

In this study, we addressed the social (i.e., disease prevalence) and individual burden of illness from OAB using clinically validated, symptom-based criteria. A surprising result from this study indicates that the prevalence of urgency-related bladder control problems is equal in men and women, although more women suffer from $\mathrm{OAB}$ with incontinence than men.

Prevalence estimates of $\mathrm{OAB}$ from previous studies have varied widely due, in part, to variation in how symptoms have been assessed, the methods used to collect the data, the criteria used to define OAB, and the population studied. This study used clinically validated symptom-based criteria to identify participants with $\mathrm{OAB}$. In the validation study, the final diagnosis was based on the clinical judgment of expert physicians, and this judgment was the foundation for the clinical validation of the CATI instrument. The validation study was conducted in a population sample similar to the sample selected for the US national survey. In addition, the CATI was developed to capture information on coping behaviors that emerge to avoid or minimize the occurrence of urinary leakage. Studies that focus on urge incontinence only are likely to exclude these individuals. The CATI survey was developed to take many of these adaptive behaviors (i.e., limited fluid intake, frequent urination, etc.) into account. Finally, in the populationbased clinical validation study, a symptom history was adequate to make a final diagnosis of OAB in almost all study participants. Therefore, the CATI provided the appropriate data to make a final disease category designation with relatively high reliability.

No previous epidemiologic study of OAB has reported prevalence in both sexes across a broad age range using clinically validated symptom-based criteria. Previous studies have focused on OAB with urge incontinence in which females were predominant. For these reasons, a comparison with other studies is limited to selected sex and age groups and either $\mathrm{OAB}$ with or without urge incontinence. In general, our female age-specific prevalence estimates of urge incontinence are similar to those of Simeonova et al. [13] and Samuelsson [12] who reported prevalence in women 20-59. Our results are similar to those of Milsom et al. [7] with respect to prevalence of $\mathrm{OAB}$ for men, but our results are higher for women. Our estimates are lower than those of Nygaard et al. [8] in a study of rural Iowa women 65 and older (prevalence of $34 \%$ ) and those of Umlauf and Sherman [16] in a study of older men. Some of the differences in prevalence compared to other studies may be explained because the NOBLE-program US survey encompassed all geographic regions of the US, and therefore was not biased by local cultural differences that may influence how candid the responders were during the interview. Milsom et al. [7] reported differences in prevalence of $\mathrm{OAB}$ from country to country and speculated that some differences in prevalence of $\mathrm{OAB}$ might be attributable to culture-related differences in how comfortable participants felt answering the interview questions.

The age-specific prevalence of $\mathrm{OAB}$ without incontinence appears to plateau after age 44 years in women and after age 54 years in men. In contrast, age-specific prevalence of $\mathrm{OAB}$ with urge incontinence continues to increase with increasing age. These contrasting age patterns suggest that $\mathrm{OAB}$ without incontinence may 
Fig. 3 Mean SF-36 scores for individuals with $\mathrm{OAB}$ with and without urge incontinence and age- and sex-matched controls

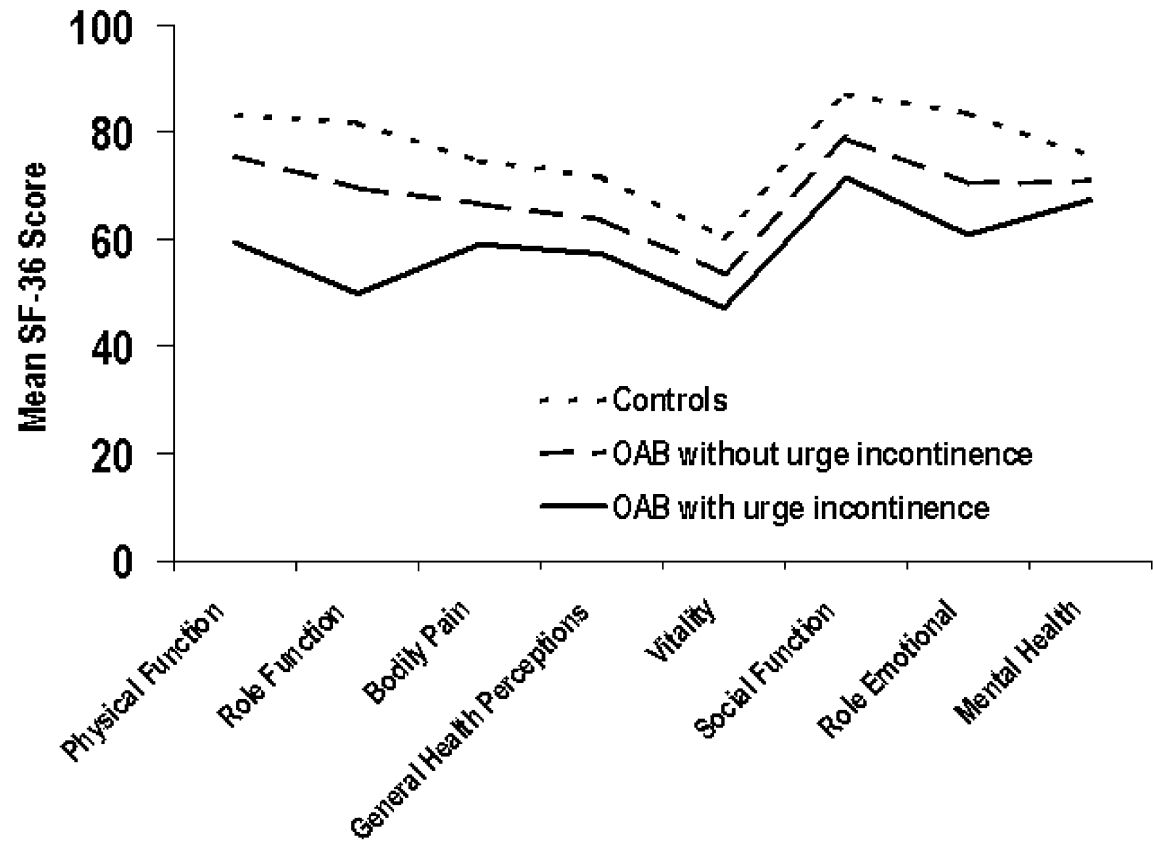

Table 3 Mean differences in measures of quality of life (SF-36), ${ }^{\text {a }}$ depression (CES-D), and quality of sleep (MOS sleep) between OAB cases and age-matched controls

\begin{tabular}{|c|c|c|c|c|c|c|}
\hline \multirow{2}{*}{$\begin{array}{l}\text { Outcome } \\
\text { Mean (SE) }\end{array}$} & \multicolumn{2}{|l|}{ Controls } & \multicolumn{2}{|c|}{$\mathrm{OAB}$ without urge incontinence } & \multicolumn{2}{|c|}{$\mathrm{OAB}$ with urge incontinence } \\
\hline & Women $(n=344)$ & Men $(n=178)$ & Women $(n=82)$ & Men $(n=146)$ & Women $(n=129)$ & Men $(n=40)$ \\
\hline \multicolumn{7}{|l|}{ SF-36 } \\
\hline Physical & $49.4(0.6)$ & $49.8(0.7)$ & $45.3(1.4)^{\mathrm{a}}$ & $46.3(1.0)^{\mathrm{a}}$ & $39.3(1.2)^{\mathrm{b}}$ & $41.3(1.9)^{\mathrm{b}}$ \\
\hline Mental & $49.7(0.6)$ & $53.6(0.6)$ & $45.1(1.4)^{\mathrm{a}}$ & $49.3(0.9)^{\mathrm{c}}$ & $46.8(1.0)^{\mathrm{d}}$ & $47.7(1.9)^{\mathrm{c}}$ \\
\hline CES-D & $11.7(0.6)$ & $7.4(0.6)$ & $17.3(1.6)^{\mathrm{c}}$ & $13.0(0.9)^{\mathrm{b}}$ & $17.1(1.1)^{\mathrm{b}}$ & $16.7(1.8)^{\mathrm{b}}$ \\
\hline MOS-Sleep & $26.4(0.9)$ & $20.1(1.1)$ & $35.4(2.4)^{\mathrm{c}}$ & $27.5(1.5)^{\mathrm{b}}$ & $38.6(1.8)^{\mathrm{b}}$ & $32.9(2.8)^{\mathrm{b}}$ \\
\hline
\end{tabular}

The SF-36 is a standardized generic HRQL instrument that measures health-related quality of life in the previous month in eight domains [physical functioning, role functioning (role of physical health in ability to carry out daily activities), social functioning, mental health, vitality, health perceptions, role emotional (role of emotional health in ability to carry out daily activities), and bodily pain]. A 5-point difference in SF-36 scores is considered clinically significant, with a lower score indicating poorer function [17]. The CES-D is a 20-item self-reported depression scale developed to

precede the onset of $\mathrm{OAB}$ with urge incontinence. Moreover, at older ages, the transition rate from $\mathrm{OAB}$ without to $\mathrm{OAB}$ with urge incontinence may exceed the rate of occurrence of new cases of $\mathrm{OAB}$ without incontinence. This may explain the plateau in prevalence of $\mathrm{OAB}$ without incontinence. Longitudinal studies will be required to test this hypothesis. If confirmed, the incidence of $\mathrm{OAB}$ with urge incontinence may be mitigated through secondary prevention efforts directed toward $\mathrm{OAB}$ without urge incontinence.

The similarity in overall prevalence of $\mathrm{OAB}$ between men and women suggests that the etiology is similar. The fact that women with $\mathrm{OAB}$ are more likely to have associated urge incontinence suggests a sex-specific cause for associated urge incontinence or, more likely, a sexbased propensity for increased severity of expression of the disease. We suspect this difference in severity is due identify depression-related symptoms. Scores range from 0 to 60 , with higher scores indicating more depression-related symptoms. Scores of 16 or greater are indicative of depression [11]. The MOSsleep is a 12-item questionnaire that measures sleep disturbance, insomnia, sleep quality and duration, and restfulness. A higher score on the MOS Sleep questionnaire indicates poorer quality of sleep [6]. ${ }^{\mathrm{a}} P<0.01 ;{ }^{\mathrm{b}} P<0.001 ;{ }^{\mathrm{c}} P<0.005 ;{ }^{\mathrm{d}} P<0.05$; all compared with controls and adjusted for differences in demographic characteristics and comorbid illnesses

to differences in the urinary continence mechanisms between men and women. Certainly some of this difference is anatomical as the female urethra is considerably shorter than the male urethra. Parity may also play a role, possibly due to neurologic injury during vaginal delivery, but additional study is needed to further evaluate this [14].

Previous clinic-based studies suggest that three health-related outcomes - HRQL, mental health, and quality of sleep - are affected by incontinence [4, 11]. However, these findings primarily reflect the experience of specialty care patients, patients who represent the more severe cases of $\mathrm{OAB}$, as well as those who may suffer from significant comorbidities. Our results are consistent with previous studies. Women and men who have $\mathrm{OAB}$, with or without urge incontinence, have significantly poorer scores on HRQL, mental health, 
and quality of sleep when compared with sex- and agematched controls. These differences were statistically significant after adjusting for other covariates, including comorbid illnesses. Finally, from the baseline interview, we compared cases and controls who returned questionnaires to those who chose to participate in the nested case-control study. Participants were representative of their respective subgroups on bladder control variables. As such, we do not believe that the differences we have observed between cases and controls in the primary outcome measures can be explained by selective participation in the nested case-control study.

The nested case-control study suggests that HRQL, mental health, and quality of sleep are moderately to severely affected in a substantial proportion of these individuals. A primary objective of this study was to understand the societal and individual impact of $\mathrm{OAB}$ and raise awareness in the face of a paradoxical view of bladder control problems. On the one hand, people with urgency-related bladder control problems are too embarrassed or reluctant to discuss the problem [3]; on the other hand, many health-care providers and consumers view bladder control problems as a normal consequence of aging. These commonly held perceptions interfere with successful clinical and self-management of OAB; increasing awareness that $\mathrm{OAB}$ is a treatable condition offers hope to those who suffer its debilitation. Similarly, health-care professionals who evaluate and treat patients with $\mathrm{OAB}$ should be aware that OAB is a highly prevalent disorder that affects men and women equally, and that $\mathrm{OAB}$ significantly lowers HRQL, even in those without urge incontinence.

Even with the strength of a unique community clinical validity study, there are inherent limitations to a telephone interview for the diagnosis of a symptombased condition like OAB. In particular, symptoms of $\mathrm{OAB}$ without incontinence (e.g., frequent urination, urgency) are common and can be explained by a number of other causes (e.g., bladder infection, interstitial cystitis, excessive body-mass index, diabetes, enlarged prostate, excessive fluid intake). As a consequence, identification of $\mathrm{OAB}$ without incontinence by telephone interview can lead to excessive false positive designations and result in an artificially high estimate of prevalence. Bladder infection is the most common cause of OABlike symptoms in women. To minimize errors we asked detailed questions about bladder infection and painful urination. Women were excluded as an OAB case if selfreported symptoms of pain on urination or a physician diagnosed bladder infection explained the presence of OAB symptoms in the previous 4 weeks. Interstitial cystitis is not likely to be a meaningful cause of false positive errors as it is uncommon in population-based studies. In regression analysis, we found no relation between $\mathrm{OAB}$ without incontinence and either BMI or self-reported physician diagnosis of diabetes. While we could not evaluate undiagnosed diabetes, it is likely that the more severe diabetics are physician diagnosed. Moreover, in our study, physician-diagnosed diabetes was reported with very high reliability (i.e., test-retest Spearman's correlation of 0.9). Finally, undiagnosed prostate problems are a possible source of false-positive errors that we could not fully account for in this study. Given these considerations, we believe that false-positive errors in the designation of OAB without incontinence did occur. We do not believe, however, that our prevalence estimates of $\mathrm{OAB}$ without incontinence are substantially overestimated. The validity study supports this notion of false-positive case designations as well as false-negative case designations. At a population level, these errors will tend to balance each other. However, estimates of disease impact from the nested case-control study are likely to be under-estimated from both of these errors.

Acknowledgements The authors thank the NOBLE Program advisory committee including J. Richard Landis $\mathrm{PhD}$, Dennis A. Revicki PhD, Karin Coyne PhD, Peggy A. Norton MD, and Christopher K. Payne MD, for their contributions. This study was supported by Pharmacia Corporation, Peapack, New Jersey.

\section{Appendix: validation of the CATI questionnaire}

\section{Participants and procedures}

A computer-assisted telephone interview of 1,552 adults in the greater Baltimore, Maryland, area was used to identify a community sample of individuals with and without the symptoms of OAB. Potential OAB cases and age- and sex-matched controls $(n=254)$ were recruited from the initial CATI survey for a clinical validation study. Participants that were recruited were over-sampled for those $>50$ years of age $(75 \%)$ to ensure a sufficient sample with bladder control problems. Participants completed a 1-week diary of their bladder symptoms prior to a clinical evaluation. At the clinic visit, a midstream urinalysis was performed and a physician conducted a semi-structured interview for the evaluation and diagnosis of OAB. Questions asked as part of the clinician's interview are available upon request. The interview began with an open-ended question about urinary habits including any specific concerns. The open-ended question was then followed by up to 58 closed-ended questions that paralleled questions in the CATI. Clinicians were free to probe as needed to clarify responses. In addition, at different points in the interview, clinicians were instructed to probe or clarify responses depending on the subject's response. The physician evaluated the level of diagnostic certainty, including an assessment of OAB-like symptoms that might be due to secondary causes. If the diagnosis was uncertain, other diagnostic procedures deemed necessary by the clinician were carried out before a final diagnosis was assigned.

\section{Clinical validation results}

Participant demographics are shown in Table 4. Based on the semi-structured interview of 254 participants, 
Table 4 Demographics

\begin{tabular}{ll}
\hline Characteristic & Participants $(N=254)$ \\
\hline $\begin{array}{l}\text { Mean age, years (SD) } \\
\text { Sex, \% }\end{array}$ & $54.2(15.3)$ \\
Men & \\
Women & 42.1 \\
Race, $n(\%)$ & 57.9 \\
White & \\
Black & $131(51.6)$ \\
Other & $110(43.3)$ \\
Missing & $10(3.9)$ \\
\hline
\end{tabular}

only $5.3 \%$ of the OAB-negative controls and $11.8 \%$ of the stress-only patients were believed to have a secondary cause sufficient to exclude a possible diagnosis of $\mathrm{OAB}$. Of those reporting OAB-like symptoms, the most common possible secondary causes of symptoms were diabetes, congestive heart failure, enlarged prostate, and pelvic organ prolapse. A follow-up visit and physical examination were required in 10 of the 254 subjects to make a final diagnosis: 8 of the 10 subjects were women and 2 were men; 9 took multiple medications (average number of medications was 6) for various medical problems; all 8 women were found to have pelvic organ prolapse; one man was found to have an enlarged prostate; after the initial interview, 4 of 10 were believed to have probable $\mathrm{OAB}$, which increased to 7 of 10 after the physical examination; 3 subjects were diagnosed as having only stress incontinence after the physical exam.

Based on the physician diagnosis, OAB without incontinence $(n=36), \mathrm{OAB}$ with incontinence $(n=71)$, stress incontinence only $(n=17)$, and normal controls $(n=130)$ provided the "Gold Standard" for determining the sensitivity (ability to correctly identify the disease) and specificity (ability to distinguish those who have the disease from those who do not have the disease) of the telephone-based criteria for OAB. The sensitivity and specificity of the telephone-based criteria for OAB compared with the clinical diagnosis were $61 \%$ and $91 \%$, respectively. The clinical validation study provided the basis for further modification of the CATI and the foundation of the validity of algorithms used to define $\mathrm{OAB}$ in the NOBLE Program studies. A profile of OAB cases with and without incontinence is displayed in Table 5.

\section{Test-retest reliability}

Test-retest reliability of individual items was assessed in a US population-based convenience sample of 231

Table 5 Profile of validity study participants by OAB symptoms and coping behaviors as reported in the phone interview

\begin{tabular}{|c|c|c|c|c|c|c|c|}
\hline \multirow[t]{2}{*}{ Variable } & \multirow[t]{2}{*}{ Category } & \multicolumn{2}{|c|}{ Controls } & \multicolumn{2}{|c|}{ OAB without incontinence } & \multicolumn{2}{|c|}{$\mathrm{OAB}$ with incontinence } \\
\hline & & $n$ & $(\%)$ & $n$ & $(\%)$ & $n$ & $(\%)$ \\
\hline \multirow[t]{4}{*}{ Urge episodes in the past 4 weeks } & $<4$ & 14 & (20.9) & 1 & $(4.8)$ & 6 & $(10.0)$ \\
\hline & $4-8$ & 16 & (23.9) & 2 & $(9.5)$ & 8 & $(13.3)$ \\
\hline & $9+$ & 37 & $(55.2)$ & 18 & $(85.7)$ & 46 & (76.7) \\
\hline & Not stated & 63 & - & 15 & - & 11 & - \\
\hline \multirow[t]{4}{*}{ Average daily micturitions } & $<9$ & 112 & $(86.2)$ & 21 & $(60.0)$ & 43 & $(61.4)$ \\
\hline & $9-11$ & 13 & $(10.0)$ & 5 & $(14.3)$ & 16 & $(22.9)$ \\
\hline & $12+$ & 5 & $(3.8)$ & 9 & $(25.7)$ & 11 & $(15.7)$ \\
\hline & Not stated & 0 & - & 1 & - & 1 & - \\
\hline \multirow{4}{*}{$\begin{array}{l}\text { Number of coping strategies used } \\
\text { for bladder control }\end{array}$} & 0 & 89 & $(68.5)$ & 16 & $(44.4)$ & 29 & $(40.9)$ \\
\hline & 1 & 32 & $(24.6)$ & 13 & $(36.1)$ & 16 & $(22.5)$ \\
\hline & 2 & 6 & $(4.6)$ & 5 & (13.9) & 12 & $(16.9)$ \\
\hline & $3+$ & 3 & $(2.3)$ & 2 & $(5.6)$ & 14 & (19.7) \\
\hline \multirow{5}{*}{$\begin{array}{l}\text { Episodes of urinary leakage in the } \\
\text { past } 4 \text { weeks }\end{array}$} & 0 & 4 & $(14.8)$ & 0 & $(0.0)$ & 0 & $(0.0)$ \\
\hline & $1-2$ & 8 & $(29.6)$ & 5 & $(62.5)$ & 4 & (7.7) \\
\hline & $3-8$ & 7 & $(25.9)$ & 3 & $(37.5)$ & 18 & $(34.6)$ \\
\hline & $9+$ & 8 & $(29.7)$ & 0 & $(0.0)$ & 30 & $(57.7)$ \\
\hline & & 103 & - & 28 & - & 19 & - \\
\hline \multicolumn{8}{|l|}{ Combined criteria } \\
\hline A. $4+$ urge episodes only & & 19 & $(14.6)$ & 5 & $(13.9)$ & 5 & $(7.0)$ \\
\hline B. $9+$ micturitions/day & & 8 & $(6.5)$ & 3 & $(8.3)$ & 2 & $(2.8)$ \\
\hline C. Use of $1+$ coping strategies & & 16 & $(12.3)$ & 2 & $(5.6)$ & 4 & $(5.6)$ \\
\hline D. $3+$ Episodes of urinary leakage & & 1 & $(0.8)$ & 1 & $(2.8)$ & 2 & $(2.8)$ \\
\hline $\mathrm{A}+\mathrm{B}$ & & 4 & $(3.1)$ & 0 & $(0.0)$ & 0 & $(0.0)$ \\
\hline $\mathrm{A}+\mathrm{C}$ & & 15 & $(11.5)$ & 6 & $(16.7)$ & 2 & $(2.8)$ \\
\hline$A+D$ & & 7 & $(5.4)$ & 0 & $(0.0)$ & 7 & $(9.9)$ \\
\hline $\mathrm{B}+\mathrm{C}$ & Not stated & 2 & $(1.5)$ & 3 & $(8.3)$ & 1 & $(1.4)$ \\
\hline $\mathrm{B}+\mathrm{D}$ & & 1 & $(0.8)$ & 0 & $(0.0)$ & 2 & $(2.8)$ \\
\hline $\mathrm{C}+\mathrm{D}$ & & 0 & $(0.0)$ & 0 & $(0.0)$ & 1 & (1.4) \\
\hline $\mathrm{A}+\mathrm{B}+\mathrm{C}$ & & 2 & $(1.5)$ & 7 & (19.4) & 4 & $(5.6)$ \\
\hline $\mathrm{A}+\mathrm{B}+\mathrm{D}$ & & 0 & $(0.0)$ & 0 & $(0.0)$ & 6 & $(8.4)$ \\
\hline $\mathrm{A}+\mathrm{C}+\mathrm{D}$ & & 5 & (3.8) & 1 & $(2.8)$ & 18 & $(25.4)$ \\
\hline $\mathrm{B}+\mathrm{C}+\mathrm{D}$ & & 0 & $(0.0)$ & 0 & $(0.0)$ & 0 & $(0.0)$ \\
\hline $\mathrm{A}+\mathrm{B}+\mathrm{C}+\mathrm{D}$ & & 1 & $(0.8)$ & 1 & $(2.8)$ & 12 & (16.9) \\
\hline
\end{tabular}


adults, with an average of 14.8 days between the 2 interviews. The reliability of the screening questions was higher for stress incontinence $(\mathrm{kappa}=0.72)$ and $\mathrm{OAB}$ with urge incontinence symptoms (kappa range 0.650.88) than for questions about urgency (kappa range $0.58-0.62)$, frequency (kappa $=0.51$ for $8+$ micturitions), or $\geq 1$ coping behaviors (kappa, 0.65). The Spearman's correlation coefficients for detailed followup questions varied by domain as follows: daytime and nighttime frequency $(0.64-0.83)$, urgency $(0.58-0.66)$, coping behaviors $(0.57-0.79)$, and urge incontinence $(0.69)$

\section{References}

1. Abrams P, Kelleher CJ, Kerr LA, Rogers RG (2000) Overactive bladder significantly affects quality of life. Am J Manag Care 6 [Suppl]:S580-S590

2. Abrams P, Cardozo L, Fall M, Griffiths D, Rosier P, Ulmsten U, Van Kerrebroeck P, Victor A, Wein A (2002) The standardisation of terminology of lower urinary tract function: Report from the standardisation sub-committee of the International Continence Society. Neurourol Urodyn 21:167-178

3. Cohen SJ, Robinson D, Dugan E, Howard G, Suggs PK, Pearce KF, Carroll DD, McGann P, Preisser J (1999) Communication between older adults and their physicians about urinary incontinence. J Gerontol A Biol Sci Med Sci 54:M34M37

4. Dugan E, Cohen SJ, Robinson D, Anderson R, Preisser J, Suggs P, Pearce K, Poehling U, McGann P (1998) The quality of life of older adults with urinary incontinence: determining generic and condition-specific predictors. Qual Life Res 7:337344

5. Grimby A, Milsom I, Molander U, Wiklund I, Ekelund P (1993) The influence of urinary incontinence on the quality of life of elderly women. Age Ageing 22:82-89
6. Hays RD, Stewart AL (1992) Sleep measures. Duke University Press, Durham

7. Milsom I, Abrams P, Cardozo L, Roberts RG, Thuroff J, Wein AJ (2001) How widespread are the symptoms of an overactive bladder and how are they managed? A population-based prevalence study. BJU Int 87:760-766

8. Nygaard I, Lemke JH (1996) Urinary incontinence in rural older women: prevalence incidence and remission. J Am Geriatr Soc 44:1049-1054

9. Pancioli AM, Broderick J, Kothari R, Brott T, Tuchfarber A, Miller R, Khoury J, Jauch E (1998) Public perception of stroke warning signs and knowledge of potential risk factors. JAMA 279:1288-1292

10. Radloff LS (1997) The CES-D Scale: a self-report depression scale for research in the general population. Appl Psychol Measure 1:385-401

11. Robinson D, Pearce KF, Preisser JS, Dugan E, Suggs PK, Cohen SJ (1998) Relationship between patient reports of urinary incontinence symptoms and quality of life measures. Obstet Gynecol 91:224-228

12. Samuelsson E, Victor A, Tibblin G. (1997) A population study of urinary incontinence and nocturia among women aged 20-59 years: prevalence, well being, and wish for treatment. Acta Obstet Gynecol Scand 76:74-80

13. Simeonova Z, Milsom I, Kullendorff AM, Bengtsson C (1999) The prevalence of urinary incontinence and its influence on the quality of life in women from an urban Swedish population. Acta Obstet Gynecol Scand 78:546-551

14. Snooks SJ, Swash M, Mathers SE, Henry MM (1990) Effect of vaginal delivery on the pelvic floor: a 5-year follow-up. Br J Surg 77:1358-1360

15. Teret SP, Webster DW, Vernick JS, Smith TW, Leff D, Wintemute GJ, Cook PJ, Hawkins DF, Kellermann AL, Sorenson SB, DeFrancesco S (1998) Support for new policies to regulate firearms. Results of two national surveys. N Engl J Med 339:813-818

16. Umlauf MG, Sherman SM (1996) Symptoms of urinary incontinence among older community-dwelling men. J Wound Ostomy Continence Nurs 23:314-321

17. Ware JE, Snow KK, Kosinski M, Gandek B (1993) SF-36 Health survey manual and interpretation guide. Nimrod, Boston 